\title{
Changes in Constituents and Ultrastructure of Hyphal Compartments during Autolysis of Glucose-starved Penicillium chrysogenum
}

\author{
By A. P. J. TRINCI AND R. C. RIGHELATO* \\ Microbiology Department, Queen Elizabeth College, Campden Hill, London, W. 8
}

(Accepted for publication 30 October 1969)

SUMMARY

The dry weight of Penicillium chrysogenum starved of an energy source decreased exponentially. The protein, RNA, DNA and endogenous respiration decreased rapidly during the first few hours of starvation and reached about $25 \%$ of their original values after 5 days starvation. The carbohydrate content of the mould only decreased after the first 2 days of starvation. About $60 \%$ of the carbon lost during autolysis was oxidized to carbon dioxide. Lysis of organelles in individual hyphal compartments occurred synchronously and did not seem to involve autophagy. Autolysis of separate compartments in the same hyphae was not synchronized. Ribosomes were rapidly degraded but membranes were particularly resistant to breakdown. Intra-hyphal hyphae were observed. In the final stages of autolysis the culture consisted largely of empty hyphal walls. A proportion of cytologically normal hyphal compartments were present at all stages, suggesting that maintenance and/or cryptic growth of some hyphae (or compartments) occurred at the expense of others.

\section{INTRODUCTION}

Righelato, Trinci, Pirt \& Peat (1968) described the cytology of Penicillium chrysogenum in growing chemostat cultures and the maintenance of the structural integrity of non-growing cells by adding glucose at the maintenance rate. The cytology and metobolism of the non-growing mould under conditions in which endogenous material provides the substrates for cell maintenance or growth are reported here.

Although several studies have been made of the endogenous metabolism and survival of bacterial cultures starved of one or more essential nutrients (see Dawes \& Ribbons, 1964; Postgate, 1967) comparable investigations with moulds are lacking. The viability of a population of unicellular organisms can usually be assessed without difficulty by the criterion of growth of individual cells. With filamentous systems such determinations are not possible and cytological criteria of the metabolic integrity of hyphal units must be used. A survey of the literature has not revealed any studies of the cytological changes accompanying starvation of moulds. Lysosomal systems form part of the cellular organization of higher animal (DeDuve \& Wattiaux, I966), protozoan (Elliott, I965), algal (Brandes, Buetow, Bertini \& Malkoff, I964) and possibly higher plant cells (McLean \& Gahan, 1968) but are not found in procaryotic cells. One function of this system is degradation of organelles, such as mitochondria, by autophagy under starvation conditions (Brandes et al. 1964). The presence of an

* Present address: Glaxo Laboratories Ltd., Ulverston, Lancs. 
analogous system in fungi is not definitely established but Thornton (I968) identified autophagic vesicles in Phycomyces blakesleeanus sporangiophores on morphological criteria. Lysosome-like vesicles have also been implicated in the secretion of extracellular enzymes by moulds (Matile, I966). However, it may be significant that golgi, which are usually involved in lysosome formation in animal and protozoan cells (DeDuve \& Wattiaux, I966) are absent from many moulds (Bracker, I967).

\section{METHODS}

The organism was Penicillium chrysogenum wis 54-I255. The chemostat growth conditions and analytical methods were as described by Righelato et al. (1968) unless otherwise stated. Dry weight and cell polymers are all expressed in terms of mould harvested from a unit volume of the culture.

Shake flask cultures. The medium was the DAN medium described previously (Trinci, 1969). The mould was grown in $250 \mathrm{ml}$. conical flasks containing $25 \mathrm{ml}$. of medium. Each flask was inoculated with $\mathrm{I} \mathrm{ml}$. of conidial suspension (final spore density, I to $2 \times 10^{6} / \mathrm{ml}$.) and incubated at $25^{\circ}$ on a rotary shaker (200 rev. $/ \mathrm{min}$.). Growth was followed by harvesting three flasks at intervals in the manner described by Trinci (1969). The dry weight of the conidial inoculum was also determined.

Electron microscopy. Mould samples were fixed in the following ways: (I) $2 \%$ (w/v) aqueous, unbuffered $\mathrm{KMnO}_{4}$ for $\mathrm{I} \mathrm{hr}$ at $\mathrm{I} 8$ to $20^{\circ}$. (2) $6 \%(\mathrm{v} / \mathrm{v})$ acrolein in cacodylate buffer at $\mathrm{pH} 7.2$ for $\mathrm{I} \mathrm{hr}$ at $\mathrm{I} 8$ to $20^{\circ}$. (3) $4 \%$ (v/v) glutaraldehyde in $0.05 \mathrm{M}$-cacodylate buffer at $\mathrm{pH} 7 \cdot 2$, overnight at $4^{\circ}$ or at $\mathrm{I} 8$ to $20^{\circ}$. Samples fixed in acrolein or glutaraldehyde were post-stained in I or $2 \%(\mathrm{v} / \mathrm{v})$ aqueous osmium tetroxide for I hr at I 8 to $20^{\circ}$. The mould was dehydrated in ethanol-water mixtures and embedded in araldite. Sections were cut with an LKB ultramicrotome with glass knives. Sections of glutaraldehyde and osmium tetroxide fixed hyphae were stained with $2 \%(\mathrm{w} / \mathrm{v})$ aqueous uranyl acetate for $30 \mathrm{~min}$. followed by an alkaline solution of lead citrate for $5 \mathrm{~min}$. (Venable \& Coggeshall, 1965). Measurements of cytological features were made directly from the photographic plates.

Acid phosphatase histochemistry. Hyphae fixed in $4 \%(\mathrm{w} / \mathrm{v})$ aqueous formaldehyde at 18 to $20^{\circ}$ were used to demonstrate the location of acid phosphatase. The method described by Jensen (I962) was followed except that 0.IM-ATP was used as the substrate instead of $\beta$-glycerophosphate. The mould samples were incubated in the substrate mixture for I to $2 \mathrm{hr}$ at $37^{\circ}$.

\section{RESULTS}

\section{Changes in hyphal constituents, respiration and dry weight during glucose starvation}

Batch, shake-flask culture. Growth of Penicillium chrysogenum at $25^{\circ}$ could be divided into lag, exponential, stationary and autolytic phases (Fig. I). Autolysis of the mould commenced when the glucose in the medium was exhausted. The dry weight of the fungus decreased exponentially during autolysis; the 'half life' of the mould dry weight was about $9 \mathrm{I} \mathrm{hr}$. The time at which the mould started to autolyse was estimated and is designated zero time. Periods before the onset of autolysis are prefixed with a minus sign, and those afterwards with a plus sign (Fig. I). This culture will subsequently be referred to as the batch culture.

Chemostat-batch culture. The medium supply to a steady state, glucose-limited culture (specific growth rate $0.05 \mathrm{I} \mathrm{hr}^{-1}$, doubling time, I4 hr) was stopped and only 
air and the $\mathrm{pH}$ control agents were subsequently fed to the culture vessel. All other essential nutrients were in excess throughout the period of glucose starvation. Immediately after termination of the medium feed the concentration of glucose in the vessel was about $0.00 \mathrm{I} \mathrm{g./l.} \mathrm{Lipids} \mathrm{and} \mathrm{glycogen} \mathrm{or} \mathrm{other} \mathrm{carbohydrate} \mathrm{reserves} \mathrm{did}$ not accumulate during glucose-limited growth, thus it was expected that when the medium supply was stopped the mould would become rapidly starved of an exogenous carbon and energy source.

The decrease in dry weight of this culture also approximated to an exponential curve and the 'half life' of the mould dry weight was about $62 \mathrm{hr}$ (Fig. 2). Rapid changes occurred in the nucleic acid and protein content of the mould when the medium feed was stopped (Fig. 2, 3). From o to +9 hr there was a linear decrease in

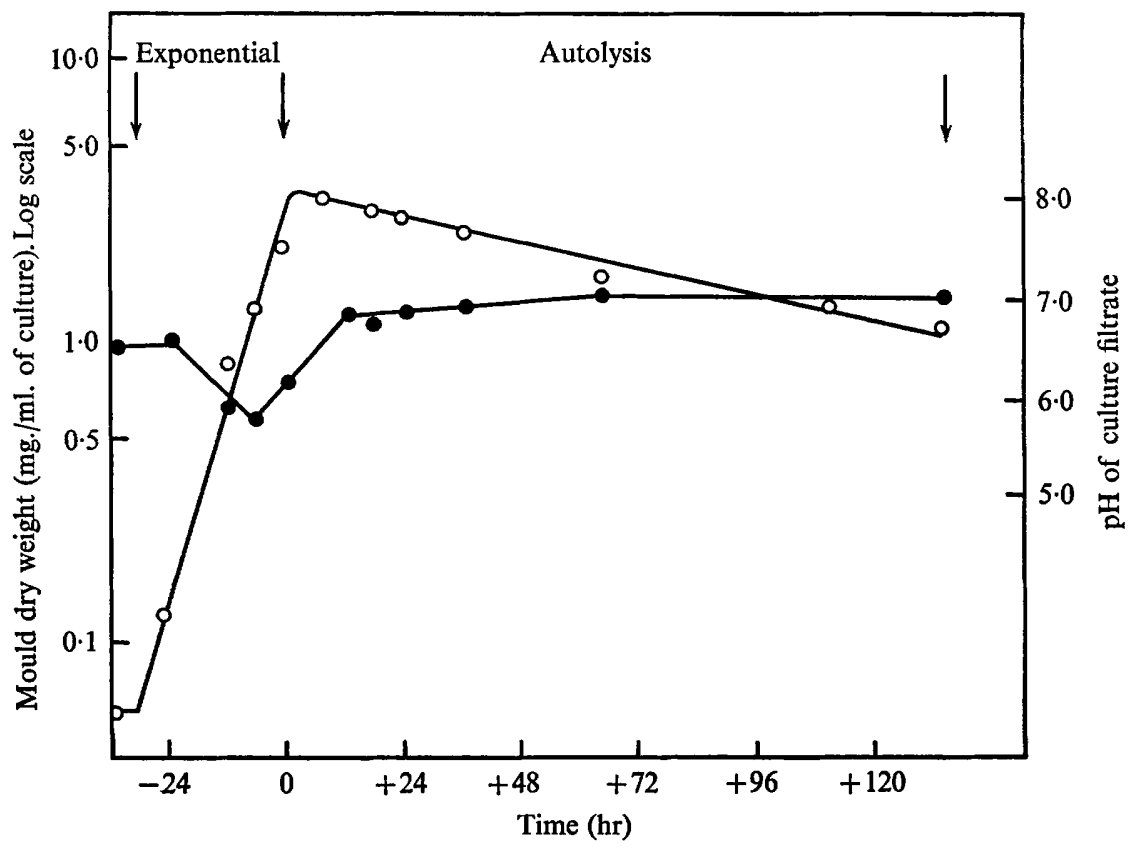

Fig. I. Batch culture of Penicillium chrysogenum grown at $25^{\circ} . \bigcirc$, dry weight; $0, \mathrm{pH}$ of culture filtrate.

the DNA content until it was about $20 \%$ of its original value, corresponding to a rate of decrease of about $9 \% / \mathrm{hr}$. The RNA and protein content of the mould decreased linearly at rates of 5.0 and $5.7 \% / \mathrm{hr}$ respectively, during the period o to $+6 \mathrm{hr}$ after which the rates of RNA and protein loss became slower (Fig. 2, 3). Ammonia accumulated in the culture medium probably as a result of deamination of amino acids released during protein degradation. Considerable quantities of $260 \mathrm{~nm}$. absorbing material also accumulated in the culture medium. The shift of this absorption band to about $285 \mathrm{~nm}$. at $\mathrm{pH}$ I 2 suggests that most of this was nucleotide bases and probably indicates that ribose was further metabolized (Beaven, Holiday \& Dawson, 1965). The carbohydrate content of the mould was approximately constant during the first 2 days of starvation (Fig. 2).

The general shape of the endogenous $q_{\mathrm{o}_{2}}$ curve (Fig. 4) is almost identical to that 


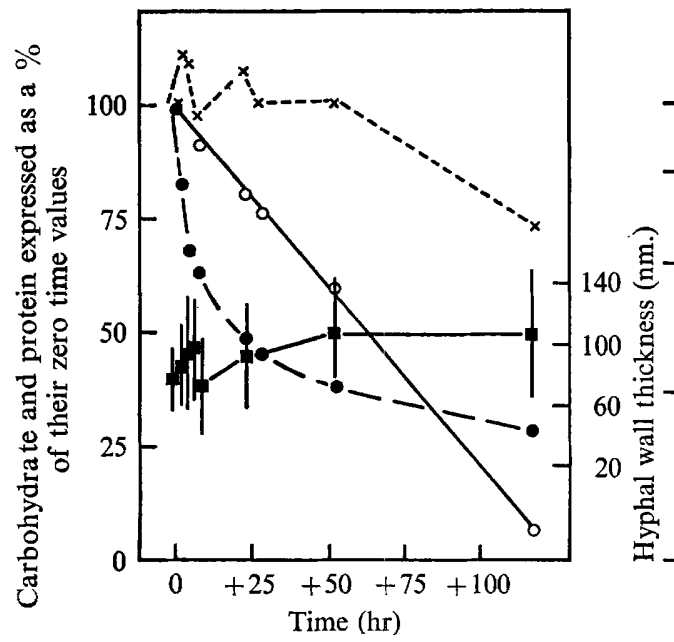

Fig. 2

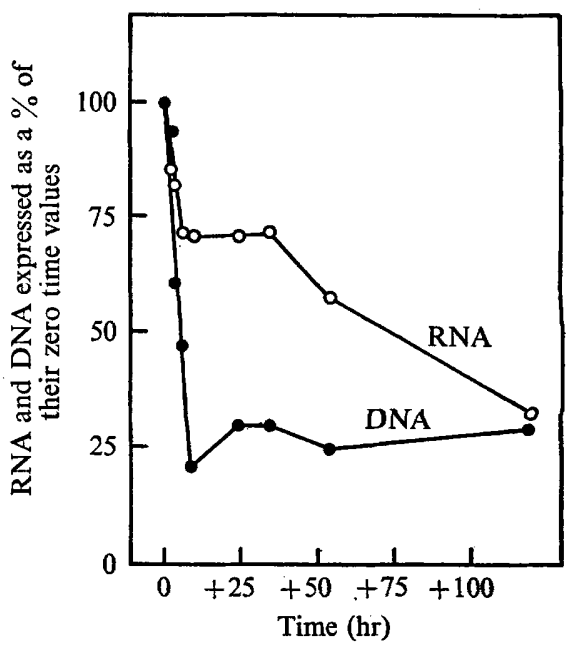

Fig. 3

Fig. 2. Chemostat-batch culture of Penicillium chrysogenum at $25^{\circ}$. Medium feed terminated at zero time. $\times$, carbohydrate; $O$, dry weight; 0 , protein; $\mathbf{\square}$, wall thickness (the vertical lines represent the standard deviation).

Fig. 3. Chemostat-batch culture of Penicillium chrysogenum at $25^{\circ}$. Medium feed terminated at zero time. RNA; $O$, DNA. DNA present after $5 \mathrm{hr}$ but too low for precise estimation.

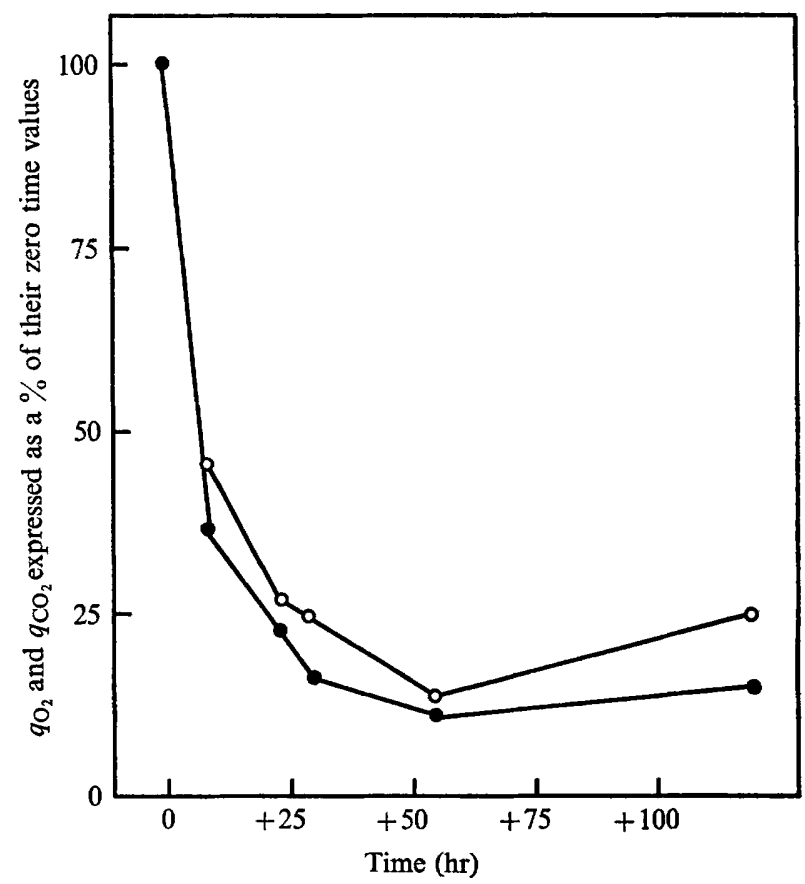

Fig. 4. Chemostat-batch culture of Penicillium chrysogenum at $25^{\circ}$. Medium terminated at zero time.,$q_{\mathrm{Co}_{2}} ; \mathrm{O}, q_{\mathrm{O}_{2}}$. 
obtained with starving cultures of Aerobacter aerogenes (Postgate \& Hunter, 1962). These workers suggest that the upward inflexion of the $q_{\mathrm{o}_{2}}$ value towards the end of the curve may be attributable to cryptic growth. The quantity of carbon lost from the culture as carbon dioxide was equivalent to about $60 \%$ of the total carbon loss, assuming that carbon constitutes $47 \%$ of the dry weight (Righelato et al. 1968).

\section{Cytological changes during glucose starvation}

The same pattern of cytological development was observed in the batch and 'chemostat-batch' cultures. The ultrastructural changes were not synchronous; some hyphae with a 'normal' cytological appearance, i.e. identical with growing cultures, were observed after 5 days starvation (Pl. I, fig. I, 2), whilst a small proportion of hyphae sampled from steady-state, growing cultures showed clear cytological signs of autolysis. Thus the cultures were cytologically heterogenous at all stages of development, and culture age could not be used as an absolute guide to the sequence of morphological events during autolysis.

Cytological observations suggest that the autolysis of some hyphae might have provided sufficient nutrients for the maintenance or growth of the remaining hyphae (Pl. I, fig. 3). This phenomenon has been observed with starving bacteria and is referred to as cryptic growth (Ryan, I955) or re-growth (Strange, Dark \& Ness, I96I). The proportion of maintained or growing hyphae decreased progressively during the starvation period. In fungi cryptic growth may, in part at least, involve the growth of hyphae within existing hyphae which are autolysing. This type of intrahyphal growth was observed in the present study (Pl. 2, fig. 4). In a few instances hyphae were observed with up to three concentric wall layers with cytoplasmic debris between them.

The 'normal' appearance of growing hyphae is shown in Pl 2, fig. 5, 6. Multimembrane, myelin-like figures, usually within vacuoles, were observed in some hyphae (P1. 3, fig. 7). It was not definitely established whether these are normal features of hyphae or represent early stages in cellular disorganization.

When this investigation was initiated it was thought that one response of the mould to carbon starvation might be the sequential degradation of cytoplasmic organelles in autolysosomes after the fashion observed in starving cultures of Euglena (Brandes et al. 1964) and other cells (DeDuve \& Wattiaux, 1966). Autolysosomes have been defined as 'membrane-lined vacuoles containing morphologically recognizable cytoplasmic components' (DeDuve \& Wattiaux, I966). Such structures have also been called cytolysosomes or autophagic vacuoles. Structures resembling autolysosomes were observed in the present study (Pl. 3, fig. 8; Pl. 4, fig. 12) but they were never very frequent and in only a few instances were nuclei observed surrounded by extra membranes (Pl. 3, fig. 9), whilst vesicle bound mitochondria were never observed. Histochemical demonstration of hydrolytic enzymes is commonly used to demonstrate lysosomes, however, ATPase activity was not demonstrated at the ultrastructural level although some positive results were obtained using light microscopy. The cytological disorganization of individual hyphal compartments $(=$ the coenocytic cell between adjacent septa) proceeded in a synchronous manner (Pl. 4 , fig. I0) rather than by sequential breakdown of individual organelles. Frequently the cytoplasm in one compartment was in a late stage of autolysis whilst that of an adjoining compartment had a normal appearance or was in an earlier stage of disorganization (Pl. 4, fig. I I). Thus autolysis of the compartments of a hyphal filament was not synchronized. 


\section{Ribosomes}

One of the early changes in the cytology of starved hyphae was that the groundplasm of glutaraldehyde and acrolein fixed hyphae became less electron-dense and ceased to have a granular texture (P1. 4, fig. I2).

\section{Nuclei}

The nucleoplasm of starved hyphae became less electron-dense and lost its granular texture except for a region which was probably the nucleolus (Pl. 4, fig. I $2 ; \mathrm{Pl} .5$, fig. 13). The shape of the nuclei and the appearance of their membranes did not seem to be affected during the early stages of nuclear disorganization (PI. 4, fig. I2). Although nuclei were occasionally observed within vesicles, nuclear disorganization was not commonly preceded by this kind of envelopment.

\section{Mitochondria}

Mitochondria commonly retained a 'normal' appearance in starved hyphae for a longer period than ribosomes or nuclei (Pl. 4, fig. I2; Pl. 5, fig. I4) although mitochondrial matrices eventually became less electron-dense. Due to this difference in the rates at which various cytoplasmic components became disorganized, mitochondria appeared more sharply delineated in starved (P1. 4, fig. I2) than normal hyphal compartments (P1. I, fig. 2; Pl. 2, fig. 6). Spherical, electron-dense bodies accumulated in the hyphae with prolonged starvation (Pl. 4, fig. IO, I2; P1. 5, fig. 15). These were sometimes membrane-bound but were too large to be Woronin bodies. Cytological evidence suggests that these electron-dense bodies may be involved in the process of mitochondrial degeneration (Pl. 5, fig. I5). Alternatively they may be lipid globules. In some hyphae, mitochondrial disorganization appeared to precede ribosome breakdown. The groundplasm of these mitochondria was electron-transparent and contained vesicles which may have resulted from the disorganization of cristae (P1. 5, fig. I6). Mitochondria with disorganized cristae were also observed in hyphae which had already lost most of their ribosomes (Pl. 5, fig. I5). In many cases the inner mitochondrial membrane appeared more electron-dense than the outer one ( $\mathrm{Pl}$. 5, fig. 13).

\section{Late stages of hyphal autolysis}

In the last stages of autolysis the hyphae contained only an accumulation of disorganized membranes (Pl. I, fig. 3; Pl. 6, fig. I7 to 19). In some cases the latter retained their characteristic 'unit membrane' appearance (Pl. 6, fig. I9). It was possible to discern the previous history of some of these membranes (Pl. 4, fig. 10). Membranes thus contain polymers, probably the phospholipids, which are particularly resistant to breakdown. There is only one reported instance of the breakdown of structural lipid during bacterial starvation (Thomas \& Batt, I969). As autolysis proceeded, the hyphae contained fewer and fewer residual membranes (Pl. I, fig. 3) until eventually only empty hyphal walls remained. Cytological evidence indicates that membrane loss may occur through release from ruptured hyphae rather than by enzymic degradation (Pl. I, fig. 3; P. 6, fig. I8). Certainly detached membranes may be detected in the medium (P1. I, fig. 3; Pl. 6, fig. I 8) and breaks in the hyphal walls were frequently observed after prolonged starvation (P1. I, fig. 3; Pl. 6, fig. I8). Membrane dispersal 
may also occur as a result of the breakdown of septa (Pl. 6, fig. 20). It is not known if wall lysis was caused enzymically or mechanically but $N$-acetylglucosaminidase, an enzyme probably involved in chitin degradation, is certainly present in Penicillium chrysogenum (Brightwell, personal communication) and may be involved in cell-wall rupture.

Conidia were not formed at any stage during the starvation period. Optimum conditions for conidia formation require a slow feed of energy source (Righelato et al. I968).

\section{DISCUSSION}

Under conditions of starvation due to limitations of exogenous carbon-and-energy source, Penicillium chrysogenum must derive its maintenance energy from endogenous material. Where no reserve material is present this involves the breakdown of functional polymeric cell components and catabolism of the monomers. Two distinct mechanisms may be envisaged; (i) the progressive utilization of components of each hyphal compartment and (ii) the rapid autolysis of some hyphal compartments providing substrates for the maintenance or growth of others.

The early loss of protein, RNA and DNA from starved Penicillium chrysogenum cultures probably took place in the majority of hyphal compartments and were similar to those shown by this organism when changing from a growing to a nongrowing state in the presence of glucose supplied at the maintenance rate (Righelato et al. 1968). In the latter case the fall in protein, RNA and DNA concentrations halted after $5 \mathrm{hr}$, whereas in the glucose-starved culture the decline continued, albeit less rapidly. The decrease in electron density and granularity of the groundplasm of starved hyphae is probably indicative of a decrease in ribosome concentration; ribosome concentration in bacteria is directly proportional to growth rate and changes rapidly with changes in growth rate (Tempest \& Strange, 1966). Protein and RNA are commonly degraded during bacterial starvation (Postgate \& Hunter, 1962; BenHamida \& Schlessinger, I966; Schlessinger \& Ben-Hamida, I966) and, as in the present study, the rate of RNA degradation is usually fastest in the early stages of starvation (Postgate \& Hunter, I962; Burleigh \& Dawes, 1967; Thomas \& Batt, I969). The ribose derived from RNA degradation is used as an energy source in bacteria (Dawes \& Ribbons, I964). Starved cultures of Aerobacter aerogenes (Strange et al. I961) or Euglena gracilis (Blum \& Buetow, 1963) can lose up to $50 \%$ of their intracellular RNA without loss of viability.

The rapid degradation of DNA in starved Penicillium chrysogenum cultures was unexpected, because in bacteria this component is either stable (Mandelstam, I960; Burleigh \& Dawes, 1967; Thomas \& Batt, 1969) or decreases by only a small amount (Postgate \& Hunter, 1962) during starvation; however, Euglena gracilis, another eucaryotic organism, also degrades its DNA during starvation (Blum \& Buetow, I963). The decrease in the electron density and granularity of the nucleoplasm of 'starved' nuclei of $P$. chrysogenum is presumably related to the observed loss of DNA, a conclusion which is supported by the fact that they were cytologically very similar to liver nuclei which had been treated with deoxyribonuclease prior to fixation (Georgiev \& Chentzov, I963).

The lack of carbohydrate degradation during the first 2 days of starvation would seem to be consistent with the fact that the thickness of hyphal walls did not decrease 
during the 5-day starvation period (Fig. 2). In bacteria it is generally believed that wall polymers (Dawes \& Ribbons, 1964) and capsular polysaccharides (Wilkinson, 1958; Duguid \& Wilkinson, 196I) do not serve as substrates for endogenous metabolism during starvation.

The degradation of cell polymers during starvation is presumably enzymic. Ribonucleases and deoxyribonucleases are present in autolysing Aspergillus niger cultures (Nagasaki, 1968), proteases in nitrogen-starved Penicillium griseofulvum cultures (Morton, Dickerson \& England, 1960) and $N$-acetylglucosaminidase in autolysing cultures of a Cunninghamella sp. (A. P. J. Trinci \& Dennis, unpublished results). In Escherichia coli the ribonucleases responsible for RNA degradation are constitutive and activated by starvation conditions (Ben-Hamida \& Schlessinger, I966).

Autolysis of most Penicillium chrysogenum hyphae occurred but some compartments retained the appearance of normal growing cells even after 5 days starvation, presumably these latter utilize the substrates released by autolysis. The fact that autolysis of adjacent compartments was not synchronized would imply that the septal pores were plugged, isolating individual compartments. There is no indication from the present work as to what determined whether a hyphal compartment would autolyse or retain its structural integrity. Autolysing hyphal compartments show a sequence of events beginning with reduction in the electron density and granularity of the groundplasm and nucleoplasm and ending in empty hyphal compartments. It would be interesting to know if there was a point of no return in this cytological and physiological sequence. The occurrence of intrahyphal growth has been reported previously (Lowry \& Sussman, 1966; Chan \& Stephen, 1967; Calonge, 1968). Calonge suggests that intrahyphal growth may occur in response to unfavourable conditions, however, in the present study intrahyphal hyphae were also observed in exponentially growing cultures. Multi-membrane, myelin like figures similar to those observed in this study have been found in other fungi (Berliner \& Duff, 1965; Hyde \& Wilkinshaw, 1966; Osumi \& Katoh, 1967; Thomas \& Isaac, 1967; Smith \& Marchant, I968; Ruinen, Deinema \& van der Scheer, I968). These structures may be artefacts (Revel, Ito \& Fawcett, 1968) and unconnected with cell lysis.

Lysosomes containing several hydrolytic enzymes have not yet been isolated from fungi. The evidence that fungi possess an autophagic system similar to that present in animal cells is wholly cytological (Bracker, 1966; Thornton, 1968). Structures which could be interpreted as autolysosomes have been observed in the present study but similar 'multi-vesicular bodies' have also been implicated in cell-wall synthesis (Marchant, Peat \& Banbury, 1967) and enzyme secretion (Calonge, Fielding \& Byrde, 1969), suggesting that the function of such structures should be interpreted with considerable caution. The present study indicates that even if autophagy occurs in Penicillium chrysogenum it does not play a dominant role in cell lysis, however, autophagy may be of considerable importance in polymer turnover during differentiation (Bracker, 1966; Thornton, 1968).

Finally we hope that as a result of this study the detection of autolysing cells in fungal cultures will be facilitated. Electron micrographs may be found in the literature which purport to be of growing hyphae but nevertheless these cells show clear signs of autolysis as judged by the cytological criteria established in this study. 
We wish to thank Professor S. J. Pirt and Dr T. D. Thomas for helpful discussion during preparation of the manuscript, and Marian Parr for technical assistance, particularly with the photography.

\section{REFERENCES}

Beaven, G. H., Holiday, E. R. \& Dawson, G. A. (1965). In The Nucleic Acids. Ed. by E. Chargaff and J. N. Davidson, vol. I, p. 493. London: Academic Press.

Ben-Hamida, F. \& Schlessinger, D. (I966). Synthesis and breakdown of ribonucleic acids in Escherichia coli starving for nitrogen. Biochimica et Biophysica Acta 119, 183.

Berliner, M. D. \& Duff, R. H. (1965). Ultrastructure of Armillaria mellea hyphae. Canadian Journal of Botany 43, I7I.

Blum, J. J. \& BuETow, D. E. (I963). Biochemical changes during acetate deprivation of Euglena gracilis. Experimental Cell Research 29, 407.

BRACKER, C. E. (1966). Ultrastructural aspects of sporangiospore formation in Gilbertella persicaria. In The Fungus Spore, p. 39. London: Butterworths.

Bracker, C. E. (1967). Ultrastructure of fungi. Annual Review of Phytopathology 5, 343.

Brandes, D., Buetow, D. E., Bertini, F. \& Malkoff, D. B. (1964). Roles of lysosomes in cellular lytic processes. I. Effect of carbon starvation in Euglena gracilis. Experimental Molecular Pathology Suppl. 3, 583 .

Burleigh, I. G. \& Dawes, E. A. (1967). Studies on the endogenous metabolism and senescence of starved Sarcina lutea. Biochemical Journal no2, 236.

Calonge, F. D. (I968). Origin and development of intrahyphal hyphae in Sclerotinia fructigena. Mycologia 6o, 932 .

Calonge, F. D., Fielding, A. H. \& Byrde, R. J. W. (1969). Multivesicular bodies in Sclerotinia fructigena and their possible relation to extracellular enzyme secretion. Journal of General Microbiology 55, 177.

Chan, C. \& StePhen, R. C. (1967). Intrahyphal hyphae in the genus Linderina. Canadian Journal of Botany 45, I995.

Dawes, E. A. \& Ribbons, D. W. (1964). Some aspects of the endogenous metabolism of bacteria. Bacteriological Reviews 28, I 26.

DeDuve, C. \& Wattiaux, R. (1966). Functions of lysosomes. Annual Review of Physiology $28,435$.

Duguid, J. P. \& Wilkinson, J. F. (I96I). Environmentally induced changes in bacterial morphology. Symposia of the Society for General Microbiology II, 69.

Elliott, A. M. (1965). Primary lysosomes in Tetrahymena pyriformis. Science, New York 149, 640.

Georgiev, G. P. \& Chentzov, J. S. (1963). An electron microscope study of the ultrastructure of isolated nuclei subjected to salt extraction. Biophysika 8,50 .

Hyde, J. M. \& WilkinshaW, C. H. (1966). Ultrastructure of basidiospores and mycelium of Lenzites saepiaria. Journal of Bacteriology 92, 1218.

Jensen, W. A. (1962). Botanical Histochemistry. San Francisco: Freeman \& Co.

LOWRY, R. J. \& SusSman, A. S. (1966). Intra-hyphal hyphae in 'clock' mutants of Neurospora. Mycologia 58, 54I.

Mclean, J. \& Gahan, P. B. (I968). Hydrolase activities in differentiating plant tissue. Biochemical Journal III, IO.

MANDELSTAM, J. (I960). The intracellular turnover of protein and nucleic acid and its role in biochemical differentiation. Bacteriological Reviews 24, 289.

Marchant, R., Peat, A. \& Banbury, G. H. (1967). The ultrastructural basis of hyphal growth. New Phytologist 66, 623 .

Matile, P. (1966). Inositol deficiency resulting in death: an explanation of its occurrence in Neurospora crassa. Science, New York $\mathbf{5} \mathbf{1}, \mathrm{x}$.

Morton, A. G., Dickerson, A. G. F. \& England, D. J. F. (1960). Changes in enzyme activity of fungi during nitrogen starvation. Journal of Experimental Botany 2, I 16.

NAGASAKI, S. (1968). Physiological aspects of various enzymes in relation to the culture age of Aspergillus niger mycelia. Journal of General and Applied Microbiology, Tokyo 14, 147.

Osumi, M. \& КАтоH, T. (1967). Oxygen-induced formation of mitochondrial membrane matrix in respiration deficient yeast. Japan Women's University Journal 14, 67. 
Postgate, J. R. (1967). Viability measurement and survival of microbes under minimum stress. Advances in Microbiological Physiology $\mathbf{1}, \mathrm{I}$.

Postgate, J. R. \& Hunter, J. R. (I962). The survival of starved bacteria. Journal of General Microbiology 29, 233.

Revel, J. P., Ito, S. \& FAwcetT, D. W. (I968). Electron micrographs of myelin figures of phospholipids simulating intracellular membranes. Journal of Biophysical and Biochemical Cytology 4, 495.

Righelato, R. C., Trinci, A. P. J., Pirt, S. J. \& Peat, A. (I968). The influence of maintenance energy and growth rate on the metabolic activity, morphology and conidiation of Penicillium chrysogenum. Journal of General Microbiology 50, 399.

Ruinen, J., Deinema, M. H. \& van Der Scheer, C. (I968). Cellular and extracellular structures in Cryptococcus laurentii. Canadian Journal of Microbiology 14, II33.

RYAN, F. J. (1955). Spontaneous mutation in non-dividing bacteria. Genetics, Princeton 40, 726.

Schlessinger, D. \& Ben-Hamida, F. (I966). Turnover of protein in Escherichia coli starving for nitrogen. Biochimica et Biophysica Acta I19, I7I.

Smith, D. G. \& Marchant, R. (1968). Lipid inclusions in the vacuole of Saccharomyces cerevisiae. Archiv für Mikrobiologie 60, 340.

Strange, R. E., Dark, F. A. \& Ness, A. G. (I96I). The survival of stationary phase cells of Aerobacter aerogenes stored in aqueous suspension. Journal of General Microbiology 25, 6I.

Tempest, D. W. \& Strange, R. E. (I966). Variation in content and distribution of magnesium, and its influence on survival in Aerobacter aerogenes grown in a chemostat. Journal of General Microbiology 44, 273.

Thomas, T. D. \& BatT, R. D. (I969). Degradation of cell constituents by starved Streptococcus lactis in relation to survival. Journal of General Microbiology 58, 347.

Thomas, P. L. \& IsAAC, P. K. (I967). An electron microscope study of intravacuolar bodies in the uredia of wheat stem rust and in hyphae of other fungi. Canadian Journal of Botany 45, 1473.

Thornton, R. M. (1968). The fine structure of Phycomyces. I. Autophagic vesicles. Journal of Ultrastructure Research 21, 269.

Trinci, A. P. J. (1969). A kinetic study of the growth of Aspergillus nidulans and other fungi. Journal of General Microbiology 57, I I.

Venable, J. H. \& Coggeshall, R. (1965). A simplified lead citrate stain for use in electron microscopy. Journal of Cell Biology 25, 407.

WiLKINSON, J. F. (1958). The extracellular polysaccharides of bacteria. Bacteriological Reviews $22,46$.

\section{EXPLANATION OF PLATES}

Abbreviations used: $A H=$ autolysing hypha; $C=$ cell wall; $D M=$ disorganized membranes; $D . M i t=$ disorganized mitochondria $; E R=$ endoplasmic reticulum; $E D B=$ electron-dense body; $G=$ groundplasm; $I H=$ intrahyphal hypha; $M=$ mitochondria; $M V B=$ multivesicular body; $M M=$ multi-membrane complex; $N=$ nucleus; $N M=$ nuclear membrane; $N P=$ nucleoplasm; $N U=$ nucleolus $; P M=$ protoplasmic membrane; $R W=$ ruptured wall; $S=$ septum; $S P=$ septal pore plug; $S R=$ septum remains $U M=$ unit membrane; $V=$ vacuole; $V M=$ vacuolar membrane.

\section{Plate I}

Electron micrographs of Penicillium chrysogenum wis 54-1255.

Fig. I. Chemostat-batch culture $+\mathrm{I}_{20} \mathrm{hr}$. Hypha with 'normal' cytological appearance. $\mathrm{KMnO}_{4}$ fixation.

Fig. 2. Batch culture +116 hr. Hypha with 'normal' cytological appearance. Glutaraldehyde fixation.

Fig. 3. Batch culture $+1 \mathrm{I} 6 \mathrm{hr}$ showing the cytological heterogeneity of the culture. Hyphae with a 'normal' cytological appearance and others which have autolysed. Some hyphal walls are ruptured and detached membranes are present in the medium. Glutaraldehyde fixation.

Plate 2

Electron micrographs of Penicillium chrysogenum wiS 54-I 255.

Fig. 4. Batch $+\mathrm{I} 6 \mathrm{hr}$ showing one hypha growing within the autolysed compartment of another. Glutaraldehyde fixation.

Fig. 5. Chemostat-batch o hr. Cytologically 'normal' hypha. $\mathrm{KMnO}_{4}$ fixation.

Fig. 6. Batch +2 hr. Cytologically 'normal' hypha. Glutaraldehyde fixation. 
Journal of General Microbiology, Vol. 60, No. 2

Plate I
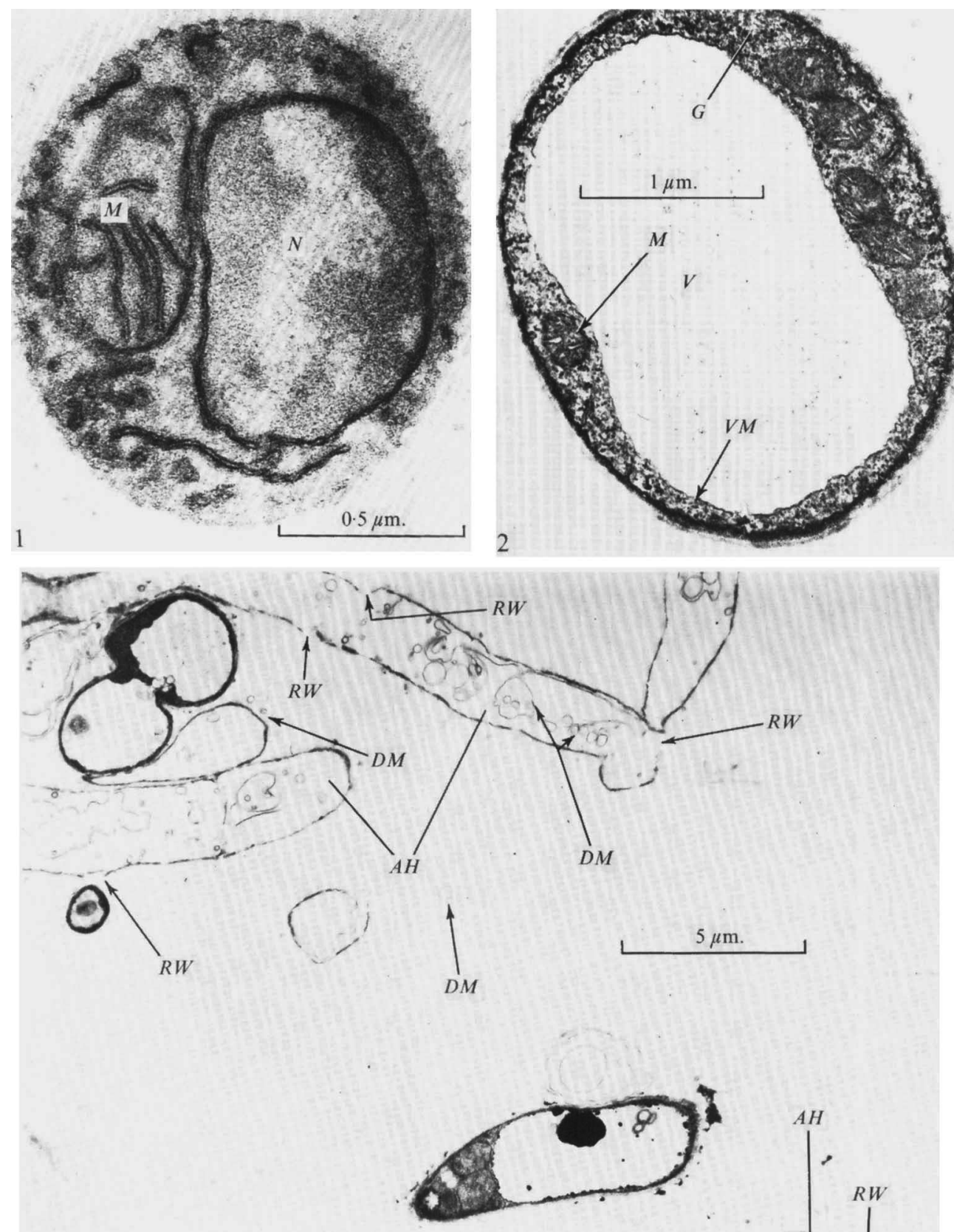

A. P. J. TRINCI AND R. C. RIGHELATO

(Facing p. 248) 
Journal of General Microbiology, Vol. 6o, No. 2

Plate 2
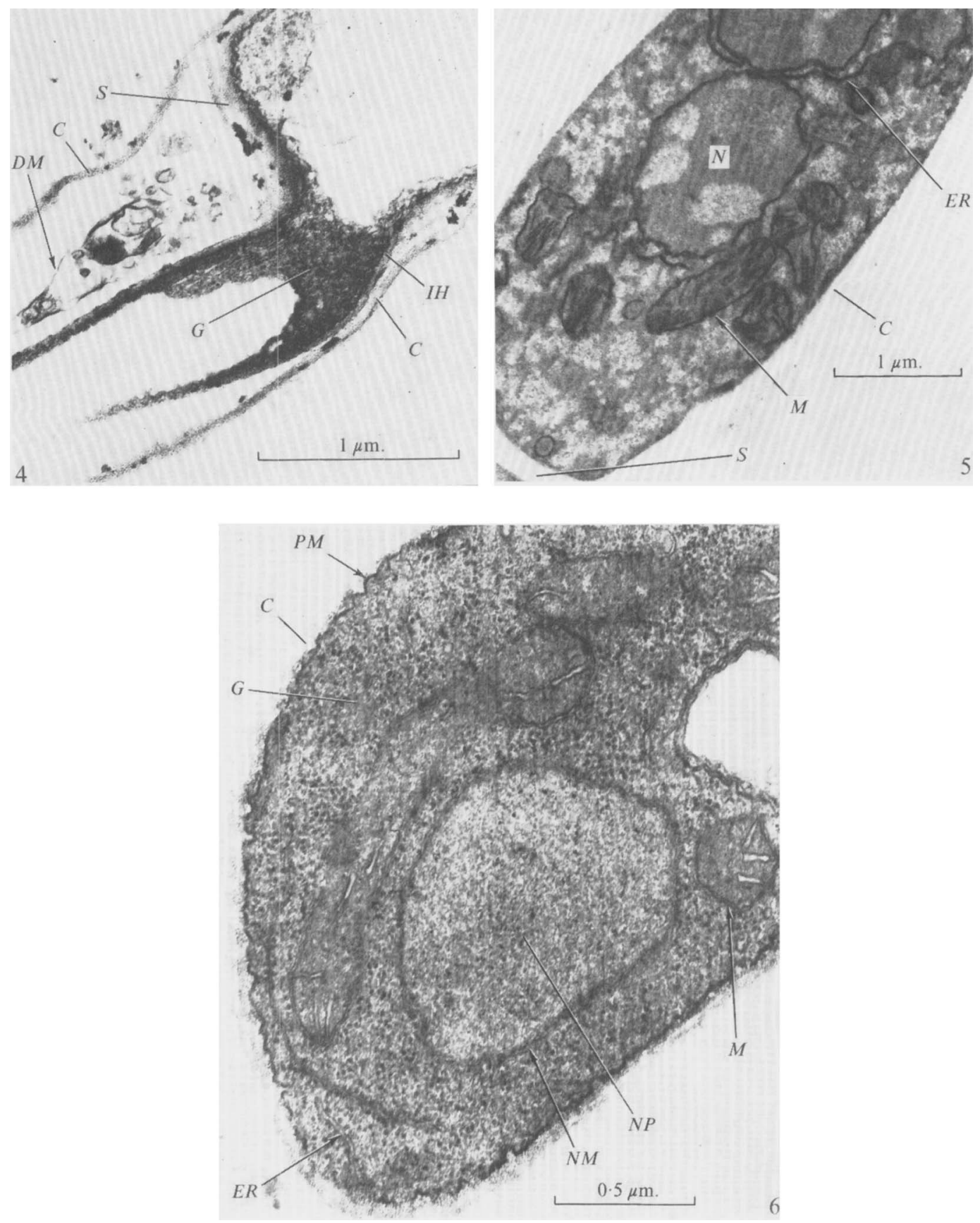

A. P. J. TRINCI AND R. C. RIGHELATO 

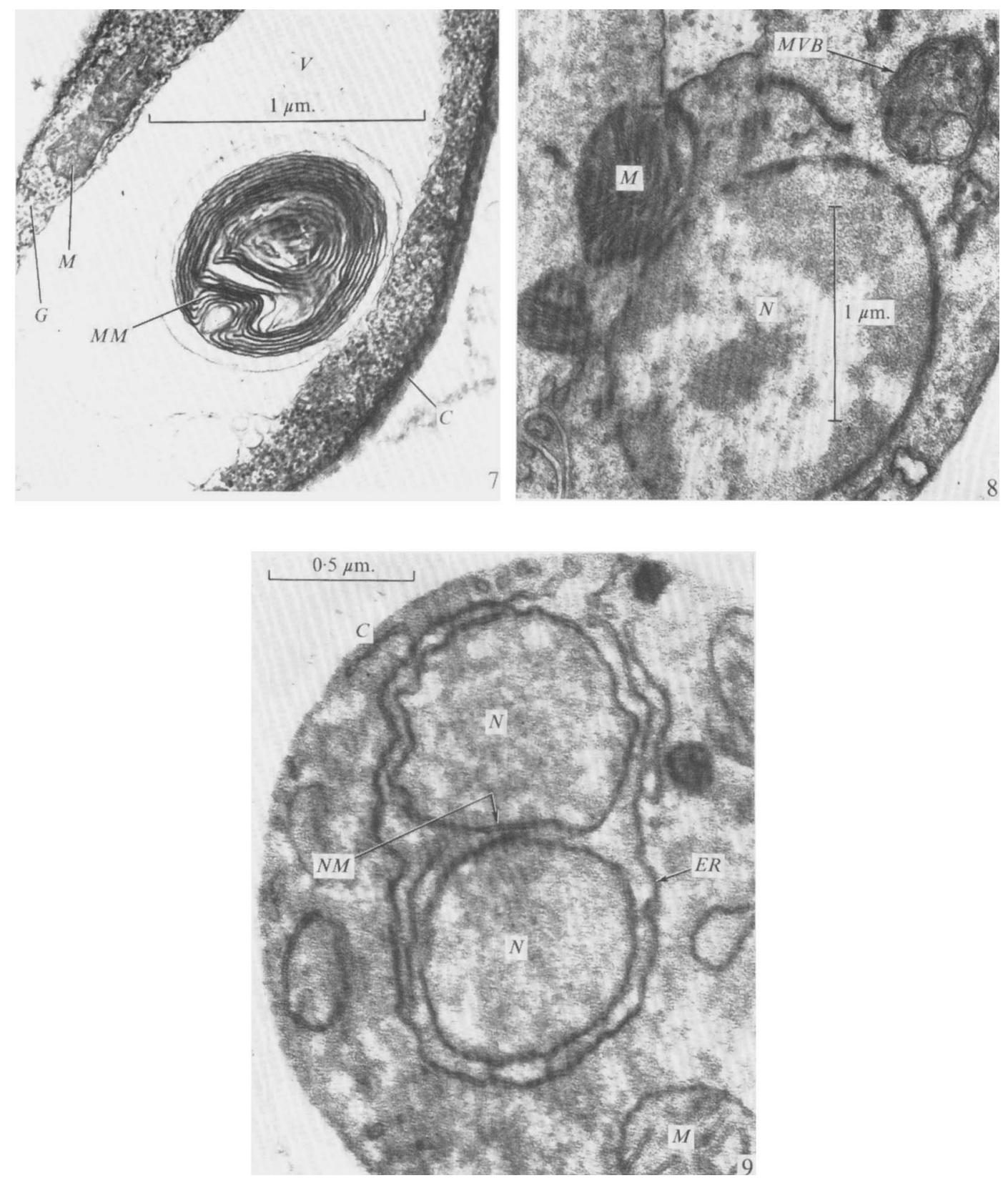

A. P. J. TRINCI AND R. C. RIGHELATO 

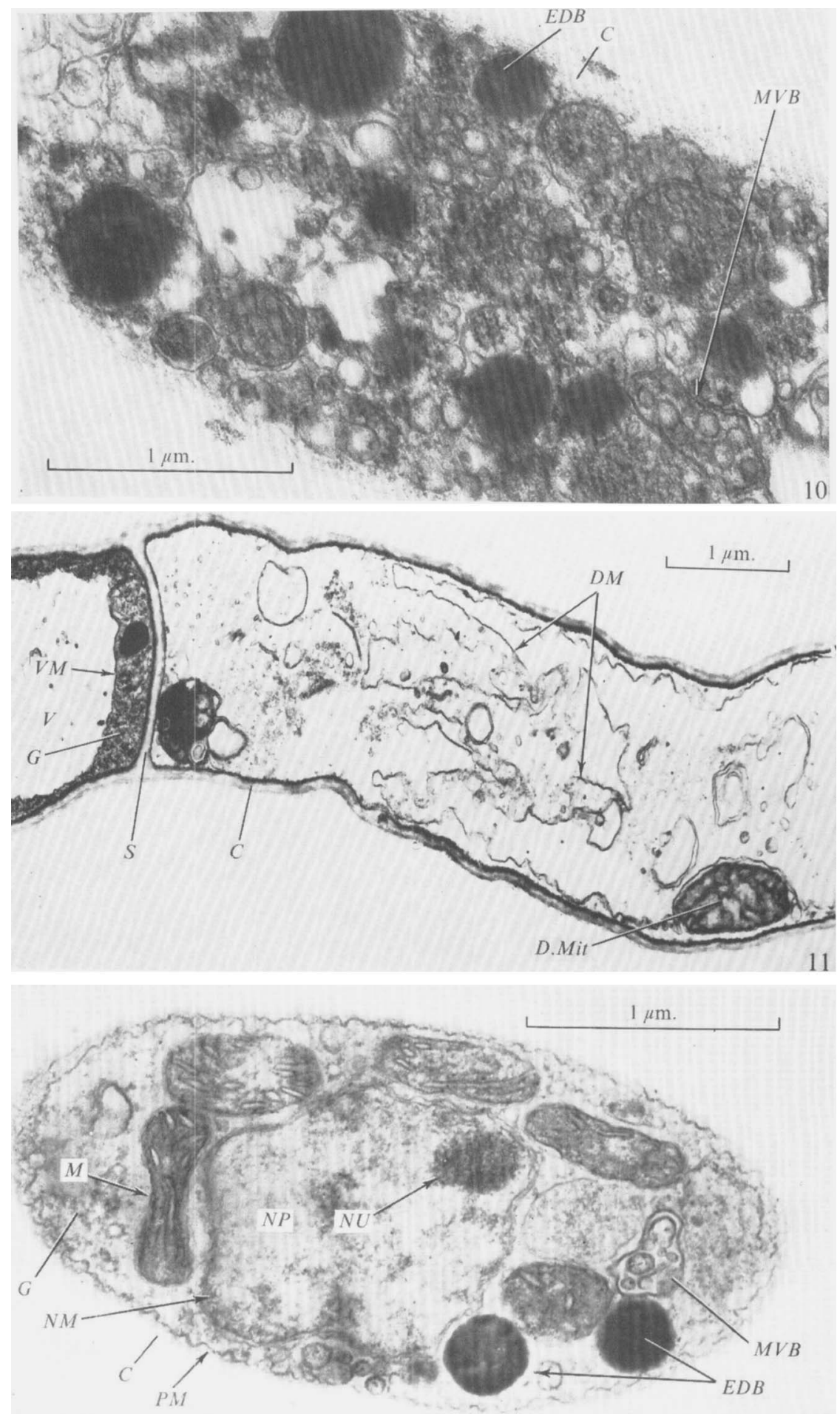

A. P. J. TRINCI AND R. C. RIGHELATO 

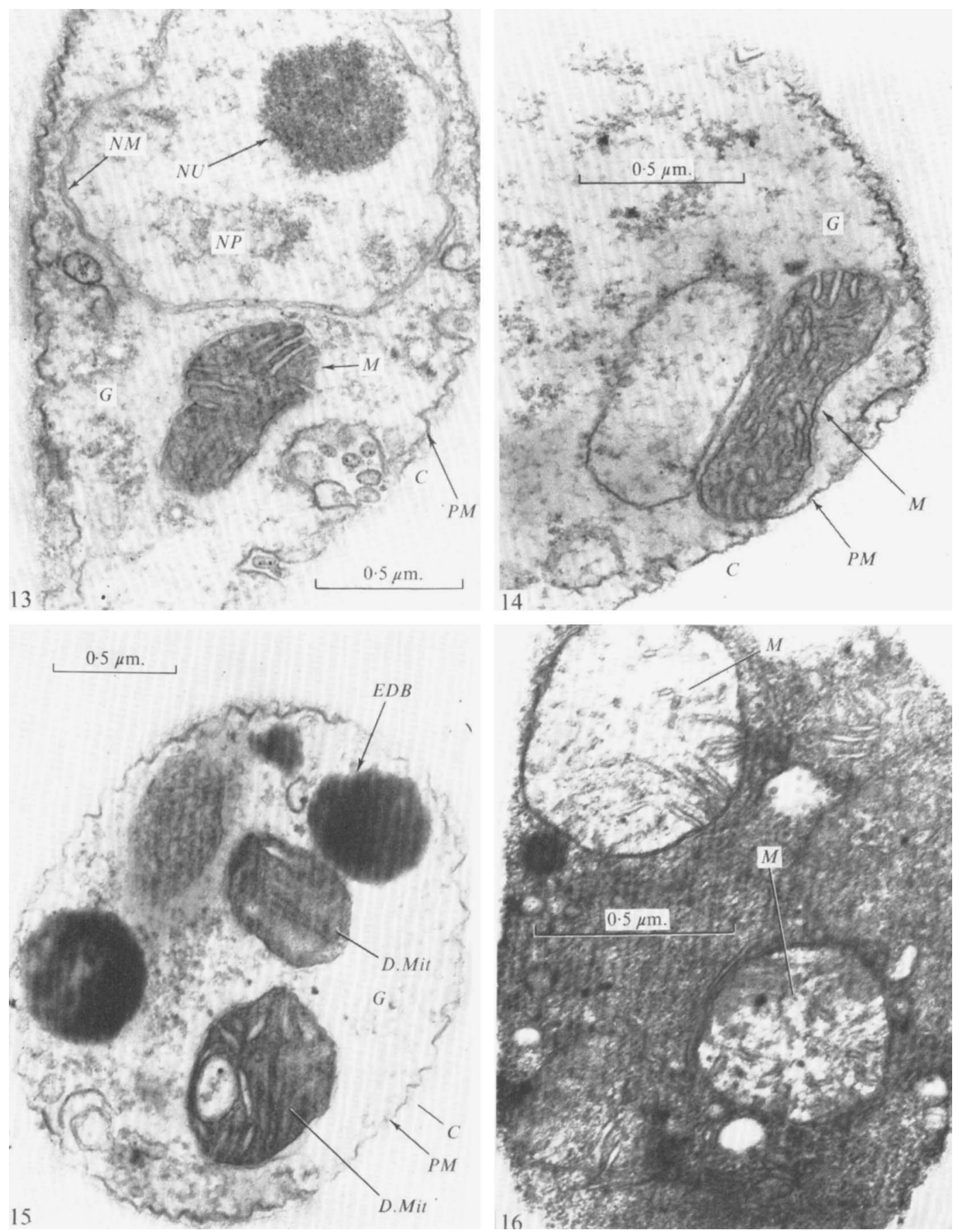

A. P. J. TRINCI AND R. C. RIGHELATO 
Journal of General Microbiology, Vol. 60, No. 2

Plate 6
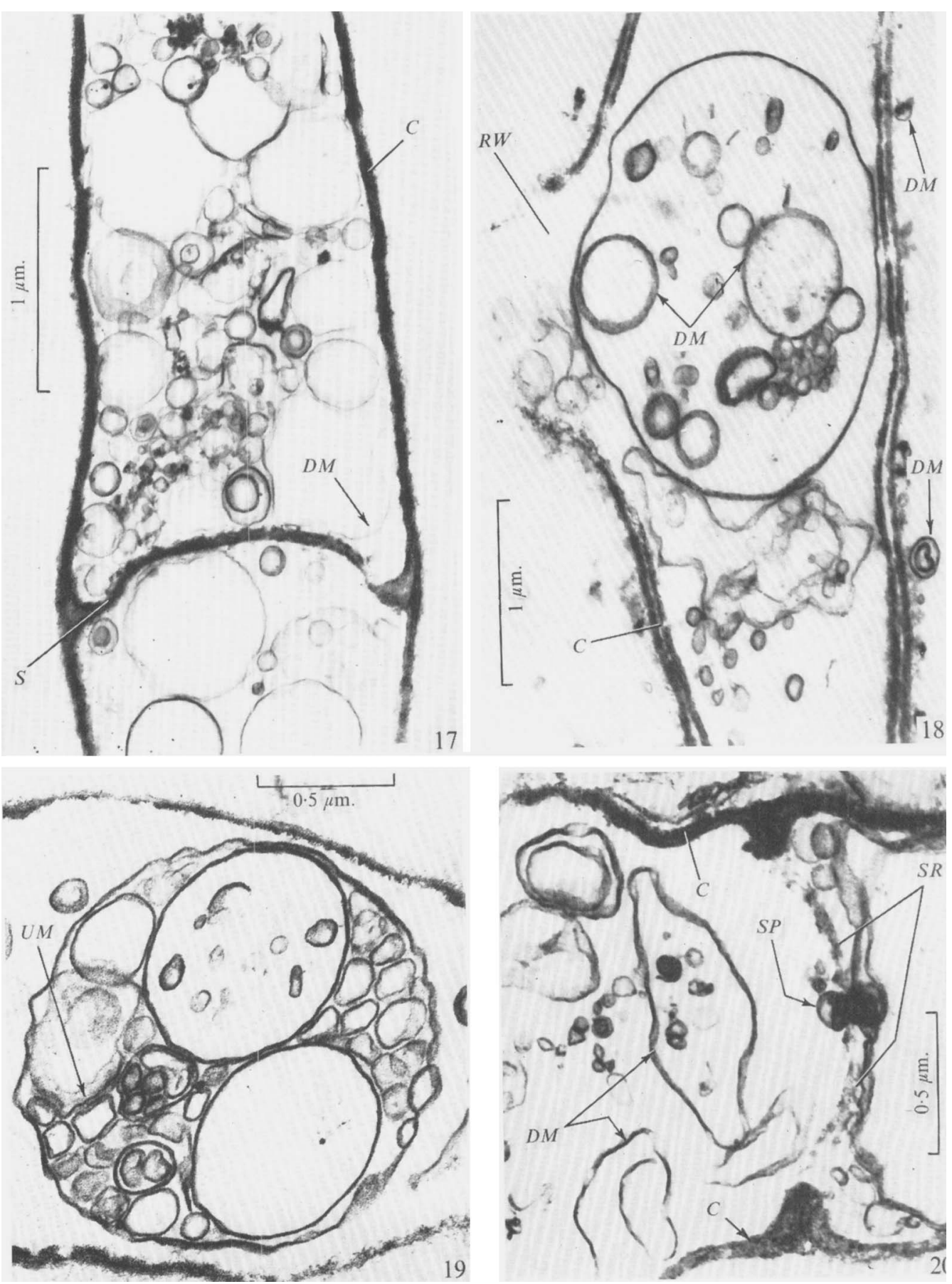

A. P. J. TRINCI AND R. C. RIGHELATO 


\section{Plate 3}

Electron micrographs of Penicillium chrysogenum wis 54-I 255.

Fig. 7. Batch $+116 \mathrm{hr}$ showing a multimembrane complex within a vacuole. Glutaraldehyde fixation. Fig. 8. Chemostat-batch o hr showing a multivesicular body which resembles an autolysosome. $\mathrm{KMnO}_{4}$ fixation.

Fig. 9. Chemostat-batch o hr showing two nuclei partially enclosed by membranes. $\mathrm{KMnO}_{4}$ fixation.

\section{Plate 4}

Electron micrographs of Penicillium chrysogenum wis 54-1255.

Fig. Io. Chemostat-batch $+\mathrm{I} \cdot 4 \mathrm{hr}$ showing a hyphal compartment which is autolysing synchronously. Acrolein fixation.

Fig. I I. Batch + I 6 hr showing an autolysing hyphal compartment adjacent to a compartment with a 'normal' cytology. Glutaraldehyde fixation.

Fig. 12. Batch +2 hr showing a hypha with an electron transparent nucleoplasm and groundplasm with few or no ribosomes. The mitochondria are more sharply delineated than in 'normal' cells. Glutaraldehyde fixation.

\section{Plate 5}

Electron micrographs of Penicillium chrysogenum wis 54-I 255.

Fig. 13. Batch $+2 \mathrm{hr}$ showing a hypha with an electron-transparent nucleoplasm and groundplasm lacking ribosomes. Some indication of a widening of the gap between the inner and outer nuclear membrane. Well-delineated nucleolus. Glutaraldehyde fixation.

Fig. I4. Batch $+2 \mathrm{hr}$. Apparently 'normal' mitochondrion and protoplasmic membrane but groundplasm lacking ribosomes. Inner mitochondrial membrane more electron-dense than outer. Glutaraldehyde fixation.

Fig. 15. Batch $+2 \mathrm{hr}$. Disorganized mitochondria in a groundplasm lacking ribosomes. Glutaraldehyde fixation.

Fig. I6. Chemostat-batch $+\mathrm{I} \cdot 4 \mathrm{hr}$. Disorganized mitochondria in a groundplasm with ribosomes. Acrolein fixation.

\section{Plate 6}

Electron micrographs of Penicillium chrysogenum wis 54-I255.

Fig. 17. Batch $+24 \mathrm{hr}$. Autolysed hypha with an accumulation of disorganized membranes. Glutaraldehyde fixation.

Fig. I8. Batch $+116 \mathrm{hr}$. Autolysed hypha with an accumulation of disorganized membranes some of which appear to be released via a rupture in the hyphal wall. Detached membranes present outside the hypha. Glutaraldehyde fixation.

Fig. 19. Batch $+116 \mathrm{hr}$. Autolysed hypha with an accumulation of disorganized membranes some of which have a unit membrane structure. Glutaraldehyde fixation.

Fig. 20. Batch +116 hr. Autolysed hypha with an accumulation of disorganized membranes. The septal wall between two compartments appears to be in the process of breakdown although the septal plug remains. Glutaraldehyde fixation. 